\title{
LA NECESIDAD DE UN TELE-HORARIO INFANTIL COMO GENERADOR DE MODELOS EDUCACIONALES
}

\section{THE NEED FOR A CHILDREN TV-TIME AS EDUCATIONAL MODELS GENERATOR}

\section{AUTOR}

\section{David Caldevilla Domínguez}

Profesor en la Facultad de Ciencias de la Información de la Universidad Complutense (España) davidcaldevilla@hotmail.com

\section{RESUMEN}

La educación infantil es una de las preocupaciones principales de toda sociedad evolucionada. La televisión desempeña un papel muy importante a la hora de formar a nuestros jóvenes. Por ese motivo le son achacados muchos de los problemas conductuales futuros, desarrollados por adultos que han pasado altas temporadas de su vida ante unos receptores que les mostraban grandes dosis de violencia y otros ejemplos igualmente reprobables. Los psicólogos afirman que a través de las cuatro fases por las que transita el niño: imitación, impregnación, desinhibición y desensibilización, se forma su personalidad.

\section{PALABRAS CLAVE}

Violencia - Infancia - Televisión infantil - Educación televisiva 


\section{ABSTRACT}

Early childhood education is a major concern of any developed society. Television plays a very important role in shaping our youth. That is why we are blamed many of the future behaviour problems, developed by adults who have been high seasons of his life to receptors that showed them large doses of violence and other examples equally reprehensible. Psychologists say that through the four stages through which passes the child: imitation, impregnation, disinheriting and desensitization, the personality is formed.

\section{KEY WORDS}

Violence - Children - Children's Television - TV Education

\section{ÍNDICE}

1. Introducción

2. La televisión en el ámbito doméstico

3. La importancia de los juegos durante la infancia

4. ¿Es la televisión la auténtica culpable de la violenta situación actual?

5. Conclusión

6. Bibliografía 


\section{Introducción}

La televisión ha sido considerada como el gran invento del siglo XX ya que ha abolido fronteras, acercado personas, transmitido valores y contenidos y es fuente inagotable de controversias tanto por sí como a su través. Ésta sería su lectura amable.

Los modelos de comunicación han evolucionado hasta adaptarse a este omnímodo canal de eventos que ha modificado, incluso, la decoración de las casas y sobre todo los hábitos de consumo de ocio.

Además, la televisión se ha convertido en un generador de economía de primera magnitud, al concentrar una gran parte del pastel dinerario de la publicidad. Salir en televisión es caro pero efectivo.

Hecha esta rápida sinopsis o plano de ubicación de la televisión en el mundo, personal y económico, pasemos a hablar de contenidos, verdadero leit motiv de los análisis comunicacionales.

\section{La televisión en el ámbito doméstico}

La televisión posee una versatilidad incuestionable en cuanto a vehiculación de temas, asuntos y, modalmente hablando, formatos. Todo esto no sería más que un campo abonado a los creativos para que postularan propuestas referidas a los tipos de programas (cada vez más perfectos dado el avance tecnológico posibilitado por los nuevos inventos) si no fuera porque su impacto social es de primerísimo orden.

Aludimos aquí a la posibilidad de informar, desinformar, entretener y, la que más nos debe preocupar: educar. 


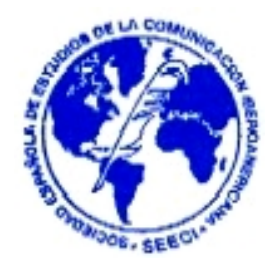

Recordemos que el niño es un ser indefenso ante ciertos impactos que pueden deformar su percepción del mundo, hacerle adquirir hábitos negativos e incluso potenciar situaciones de riesgo para su persona y psique en formación. Los padres han de velar porque este continuo asalto a sus consciencias sea adecuado a sus capacidades y acorde a sus intereses y necesidades. La televisión puede desempeñar una función que va desde aliado inestimable a enemigo declarado con una pasmosa facilidad para mudar su faz.

Centrándonos en los aspectos más negativos, hemos desarrollado un análisis de las emisiones de las televisiones de diversos países de nuestro entorno, y, siguiendo la línea de varios pedagogos y psicólogos hemos extractado conclusiones para elaborar un fresco de la cotidianeidad a la que se ven enfrentados nuestros niños. Trataremos de evitar los tópicos e ideas preconcebidas sobre los efectos (generalmente nocivos) de la televisión en nuestras mentes y centraremos estas páginas sobre el eje gravitacional del peso que esta influencia catódica puede generar en los infantes tanto en su presente como en los efectos previsibles en su futuro.

El punto de inicio es la violencia. Hemos tomado este fiel de la balanza a fuer de intentar reflexionar como algo tan nocivo para la convivencia se mete por los entresijos de nuestra consciencia para anidar en zonas de más difícil acceso de nuestra mente. Todos hemos sido niños y todos hemos consumido horas de programación con contenidos poco adecuados. ¿Será la televisión, el electrodoméstico con más poder de la casa, el responsable último de algunas conductas asociales dentro de nichos poblacionales ya tendentes o predispuestos históricamente (según las estadísticas) a sufrir y hacer sufrir a los demás ciertas acciones y conductas consideradas negativas?.

La violencia que llega a través de la pantalla hasta el niño sigue estos cuatro procesos hasta su asimilación e integración en su comportamiento, según ha expuesto la institución francesa "Centro Internacional de la Infancia": 
1. La imitación: Por medio de ella, el niño se identifica con un personaje, copia de él su comportamiento y adopta sus opiniones.

2. La impregnación: El proceso de asimilación y de imitación es inconsciente. El niño no tiene oportunidad de escoger su modelo.

3. La desinhibición: Con las imágenes apropiadas se favorece en el niño el paso de la contemplación al acto.

4. La desensibilización: La repetición de los actos violentos provoca en el niño una apatía que le lleva a considerar normal la violencia.

Los españoles gastamos unas 17.000 pesetas al año en juguetes para los niños menores de 11 años. Los Estadounidenses unas 36.000, aunque hay que ponderar los diversos niveles de vida de ambos países (es decir, en porcentaje de renta no estamos tan separados y también EE.UU. posee un nivel tecnológico superior incluso en los tipos de juguetes en venta).

\section{La importancia de los juegos durante la infancia}

Desde que nacen hasta que van al colegio los niños juegan unas 17.500 horas de media. Lo aconsejable es que dediquen 6 horas diarias al juego los niños de siete años y tres los de once.

Todos los psicólogos reconocen que es más importante el hecho de jugar que el juego y el juguete en sí. Esto es así porque al poner la tecnología al servicio de los niños, aparte de jugar, se forman. Hablamos de una tecnología de base que es similar (aunque simplificada) a la que se enfrentarán años más atrde en su proceso de formación y madurez.

Según la pedagoga Maite Romero, los juguetes bélicos no son nocivos para la educación porque tienen un valor simbólico, al igual que cuando se juega a médicos 
o casitas. No obstante, el Defensor del Pueblo en España ha intervenido, fiscalizando alguna empresa juguetera, al ver lo perfecto de algunas de las imitaciones de armas fabricadas y comercializadas por dichas mercantiles.

Cuanto más se tome en brazos y se acaricie a un bebé, más feliz se sentirá, pero el afecto es fundamental a cualquier edad. Hay que abrazarlo muy estrechamente. La ausencia de afecto maternal en un niño puede producir retraso emocional. Esta necesidad es casi tan poderosa como la del propio alimento. La calidad de los afectos es aún más importante que a mera cantidad.

Según Bernabé Tierno (psicopedagogo) "La familia ha de concienciarse al completo de que la televisión es sólo un tipo más de actividad disponible, como lo es jugar, leer o correr". Para Frangois Mariet en su libro Déjenlos ver la Televisión (1994), la realidad es muy otra: La televisión es una influencia positiva que usada con moderación, incentiva la inteligencia. Sin embargo los padres le otorgan un grado de libertad sorprendente y las más de las veces su uso no se vigila. La televisión convierte a los pequeños de la casa en blanco de publicidad, limitando su fantasía e individualidad.

Los efectos de la violencia televisiva no están definidos con precisión, pues hay ciertas variables que influyen en los resultados como los son el tipo de violencia que se exhibe y las características del niño. Lo que si parece claro, para los expertos, es que ejerce un efecto desinhibidor sobre la agresividad y que instruye sobre nuevos métodos para expresarla. A largo plazo puede tener que ver con la indiferencia del niño ante los efectos de la agresión 0 ante el dolor ajeno, lo que le llevará a la insolidaridad o a la asocialidad (claro está que en casos muy extremos).

Alejandro Perales, presidente de la Asociación de Usuarios de la Comunicación opina que "achacar la violencia a la televisión es simplista pues si algo es arraigado a la naturaleza humana, la televisión normalmente lo refleja", en cambio Lolo Río, en su 


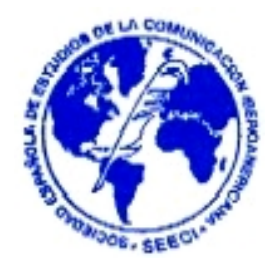

libro Televisión, fábrica de mentiras (1998) afirma "es imposible que quien a los 16 años ha visto tanta violencia no participe de algún modo en ella".

En las casas donde la televisión no tiene limitado su horario, no queda tiempo para leer, charlar con los padres o jugar. La televisión es usada como chacha barata, como canguro permanente y como aya no sindicada. Se viene hablando mucho de generar unas franjas horarias de autocontrol o autocensura coincidentes con el horario infantil ante el televisor. De esta forma quedarían prohibidos ciertos contenidos en los momentos de mayor afluencia infantil ante la pantalla, relegando el resto de contenidos (violencia, sexo y publicidad agresiva, especialmente) a las horas más propias de adultos.

Bien es cierto que uno de estos grupos de científicos -no recuerdo cuál concretamente- sostenía la teoría de la naturaleza materna de la televisión basándose en el hecho del terror que produce al niño pasar períodos enteros sin la presencia de su madre, lo cual se veía compensado antaño con la presencia de una sustituta fuera la abuela o la niñera, a la que el bebé aprendía a tolerar en ausencia de su progenitura y con la que intimaba a nivel afectivo y de juego para el desarrollo de todas sus habilidades, hasta llegar a los catorce, quince o dieciséis años que era cuando el niño, indefectiblemente, daba por cerrado su tiempo de juego para pasar a mantener relaciones más cercanas a lo adulto.

La televisión podía lograr lo mismo que una niñera (tener entretenido al niño sin riesgos físicos) con unos costos ridículos en comparación. En términos deportivos: Televisión 1-Niñeras 0. 


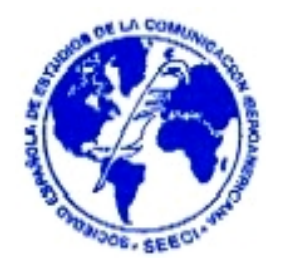

\section{4. ¿Es la televisión la auténtica responsable de la violenta situación actual?}

Pero no todo eran parabienes para con el denostado tubo catódico de imágenes en movimiento (que ya de por si es un fraude, pues no hay movimiento en las imágenes sino credulidad en la retina). Muchos veranos familiares en la ciudad han sido achacados a su desmedido uso y abuso en la mente de los padres naturales de las criaturas teleadictas. La televisión fue vista desde entonces como la gran embaucadora, la sirena de Ulises que lo lleva por las sendas del proceloso suspenso que era la causa del estío urbano. Quizás otra cara de la leyenda negra televisual, pero, por esta vez, sí parece tener una relación propia del doble vínculo, causaefecto, no tanto en cuanto a contenidos impropios como a la estajanovista dedicación espectadora de los niños.

En Francia, desde hace un año, la televisión se ha puesto de largo y ha comenzado a emitir cierta serie de programas que versan sobre la filosofía y otras áreas del saber antes vedadas o simplemente acotadas a espacios minoritarios en duración y franja horaria.

Los estudios de la Clínica para las Alteraciones de la Comunicación de Maguncia, en Alemania, afirman en un estudio del 1997 que el 25\% de los niños entre cuatro y seis años sufre problemas de articulación al hablar. La principal culpable, según ellos, no es otra que la televisión, porque mantiene a los niños en un estado pasivo que los convierte en seres cada vez menos hábiles oralmente. Se afirma incluso sin cobijo a la duda que la influencia de la televisión es más peligrosa en los primeros cuatro años de vida.

El profesor Miguel Contreras, profesor en la Facultad de Ciencias de la Información de la Universidad Complutense, antiguo responsable de programación de TeleMadrid hasta 1993, comentó al respecto, en unas jornadas celebradas en dicha institución, 
que uno de los grandes programadores de los EE.UU. en una conferencia ofrecida para sus homólogos europeos los hizo reflexionar sobre un hecho asombroso a la par que fortuito en su descubrimiento: "La violencia en los barrios neoyorquinos estaba relacionada de una manera directamente proporcional al aumento del número de lavadoras vendidas e instaladas en las casas particulares". Este extremo, según el analista estadounidense había sido comprobado personalmente por él durante un periodo de 3 años.

Según Contreras, esta afirmación se había basado en la incuestionable veracidad de la estadística de los albores del siglo XXI.

"Hace tiempo, continuó Contreras, que este programador norteamericano había comentado a los programadores de las parrillas de televisión que podíamos tener la conciencia intranquila al ser acusados de llenar la mal llamada caja tonta de contenidos capaces de crear entre la audiencia seres disléxicos, dislálicos, obtusos, atontados, violentos, amén de demás enfermedades relacionadas con la vista. Por ello se encargó una encuesta en los EE.UU. en la que se trató de analizar si la violencia aumentaba con las horas pasadas ante la televisión o con la compra de ésta o con cualesquiera otras circunstancias, pues era esta caja de imágenes fugaces la culpada de los espectaculares aumentos de violencia en aquellos años ochenta en los EE.UU.. Se comprobó que en los barrios donde la venta de lavadoras había aumentado se había incrementado de manera análoga la violencia habitual entre sus habitantes. ¿A alguien lo tomaríamos en serio si afirmara axiomáticamente que el incremento en la venta de lavadoras hace aumentar los índices de violencia de un barrio?. ¿Estamos, por tanto, ante el electrodoméstico de más poder sobre la vida y la muerte después de la silla eléctrica?". 


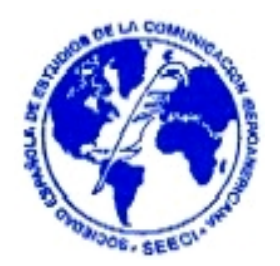

Tales fueron sus conclusiones.

La violencia estudiada en su esencia nos dice que en España un teleadicto asiste, en sus 25 horas semanales de televisión, a 670 asesinatos, 420 tiroteos, 30 torturas cada semana de año (fuente INE). Por lo tanto, un niño medio de 10 años ha podido presenciar 8.000 asesinatos en su corta vida y de los que ha sido consciente. Esto no es nada si tenemos en cuenta que en los últimos 5.600 años de historia escrita, ha habido unos 14.531 conflictos bélicos con sólo 292 años de tregua y más de 3.640.000.000 de víctimas. La televisión sólo puede tener la culpa de lo acaecido desde hace 50 años, y no en todo el mundo.

Rojas Marcos, psicólogo jefe del Ayuntamiento de la ciudad de Nueva York, afirma que "nacemos con una profunda capacidad y deseo de imitar", algo con lo que los psicoanalistas están muy de acuerdo, como el profesor González Requena en su El discurso televisivo, espectáculo de la posmodernidad (1988). Diversos estudios afirman que se ha demostrado que bebés de 14 meses ya comienzan a imitar los gestos que ven en la televisión, por lo que sí parece sensato pensar que los medios de comunicación desempeñan un papel determinante en la formación de la personalidad.

Los psicólogos Bandura y Walters estudiaron el efecto de los distintos tipos de agresión:

1. El primer grupo vio como un adulto maltrataba a una muñeca de goma en directo.

2. El segundo vio lo mismo, pero a través de un televisor.

3. El tercero en una película de dibujos animados.

4. El cuarto no presenció agresiones. 
Tras el visionado se permitió a cada grupo jugar independientemente y más tarde en conjunto y se estudió la forma en que lo hacían.

Los menos agresivos fueron los que no habían visto violencia (grupo cuarto) pero de los otros tres grupos, los más violentos fueron los del grupo segundo (es decir, los que habían visto la violencia a través de un televisor).

Retomando las ideas de Rojas Marcos, recordamos que él ha afirmado "particularmente prefiero echar la culpa de la violencia infantil a la serotonina o a la testosterona (que hace que los niños sean más violentos) y que son propias de nuestra naturaleza que echárselas a la televisión".

Federico Allodi, psiquiatra cordobés, profesor de la Universidad de Toronto y Fundador del Centro Canadiense para las víctimas de la Tortura, ha escrito "lo que ocurre con la televisión es que, si los programas enseñan a los niños que la violencia es buena solución, ellos actuarán violentamente. Pero si dejan claro que es una fantasía, sabrán que no se puede hacer".

Los expertos confirman que al igual que se puede convertir a un niño en lector empedernido si desde pequeño, desde sus primeros años de vida, se le leen cuentos e historias, también se puede hacer de él un ser violento si se utilizan los medios adecuados. La discrepancia surge en la visión final de las cosas, es decir, ¿Existen productos culturales capaces de facilitar la creación de un violento?

En Francia, país muy sensibilizado con el tema violencia/infancia, la revista Le Point (E/ Punto) contabilizó en el mes de Octubre de 1988 (con tres cadenas estatales emitiendo en Francia: TF1, Antenne 2 y TF3 y tres privadas: Tele 5, TM 6 y Canal +) todos los actos violentos que podían contemplarse durante una semana. Los resultados fueron: 
- 670 muertes

- 15 violaciones

- 848 peleas

- 419 explosiones

- 14 raptos

- 32 tomas de rehenes

- 27 escenas de tortura.

Es decir, un acto violento cada 5 minutos. Este dato invita a la reflexión de los modelos sociales (ficticios, podríamos apuntillar) que más impactan al espectador y que más lo atraen ante la pantalla. ¿Nos gusta lo que nos dan o nos dan lo que nos gusta?...

Lo que es indubitable es que la televisión (y el cine, como su hermano mayor, al menos en edad) es el vehículo perfecto para transmitir contenidos de impacto. En este caso es visual, que es la forma más fiel de transmitir la acción. Paradójicamente las imágenes violentas reales (las de documentales o los telediarios) no suelen ser del gusto de la mayoría del público, por lo que se constata que la violencia real agrada menos e incluso ofende. Por ello, y si unimos a la pantalla las posibilidades técnicas de 'inventar' mundos, seres, acciones imposibles $y$, en general, recrear situaciones de riesgo sin que exista realmente tal, afirmaremos que los efectos especiales son los verdaderos reyes de la programación/creación audiovisual, con lo que de aséptico tienen.

Las películas de directores como Sam Peckimpah ("Duelo en la Alta Sierra" -1961-, "Mayor Dundee" -1965-, "Grupo Salvaje" -1969-, "La balada de Cable Hogue" -1970-, "Perros de paja" -1971- y "Pat Garrett y Billy el niño" -1973-, por citar las más conocidas) o su sucesor espiritual Quentin Tarantino (guionista de "Asesinos natos" 1994- de Oliver Stone o "Abierto hasta el amanecer" -1995-de Roberto Rodríguez entre otras y director de "Reservoir dogs" -1993- y "Pulp Fiction" -1995-) se basan en 
un empleo sustantivo de la ultraviolencia, lo que les lleva a una media constatable de unos 50 asesinatos o muertes violentas a la hora (verbi gracia "Asesinos natos").

En la película "El último gran héroe" -1993- de John Mac Tiernan, el protagonista, Arnold Swarzzeneger, se excusa de la carencia de excesivas muertes y actos violentos en la película de acción que acaba de rodar como actor (la trama va de una película dentro de otra) aduciendo que ha decidido prescindir de esos alicientes 0 aditivos a la historia ante su público, ultraadicto a la acción violenta, para sustituirlos por una acción más controlada, una historia de más peso y unos efectos especiales más impactantes.

\section{Conclusión}

El éxito que tienen las películas de terror y de violencia (lo gore en su estado hipertrofiado) se debe, según los psicoanalistas, a un fenómeno de proyección como tránsfer idílico y onírico, es decir, de identificación y liberación. Connie Zweig afirma: "esa identificación con el personaje en el que delegamos la carga emocional libera nuestros impulsos perversos en el entorno seguro que nos ofrece un libro o una película". ¿Es bueno suavizar los cuentos infantiles para evitar la violencia?, Connie Zweig cree que Caperucita Roja no debe reescribirse a fin de que el niño afronte el mal, con el que al fin y al cabo, se encontrará en su vida real.

Capítulo a parte merece el género japonés llamado 'Manga', como mayor ejemplo de representación vicaria de la violencia.

Los estudios de Roswell Huesmann en 1985 y de Tannis Williams de 1986 trataron de demostrar que existe una relación muy estrecha entre el consumo de lo audiovisual y el aumento de la agresividad social.

Así, Roswell Huesmann (Illinois) estudió la situación de seis países: EE.UU, Australia, 
Finlandia, Israel, Países Bajos y Polonia. Su conclusión fue que en todos ellos, la violencia televisada propiciaba un aumento generalizado de la agresividad infantil.

Tannis Williams (Columbia Británica Canadiense) demostró que la agresividad era mayor en los pueblos con televisión que en aquellos que no tenían. El impacto de la televisión sobre la psique es notorio y los resultados de los estudios son claros, según sus trabajos. El espectador participa emocionalmente de la acción del héroe. Los electroencefalogramas han detectado que las hondas alfa del cerebro siguen los movimientos del actor quien mediante ellos, incita al espectador a seguirlo. Asimismo, un oculograma muestra que la persona espectadora presenta las mismas reacciones emocionales que el actor.

Muchos tecnopolicías y ciberdelincuentes pero ningún ingeniero.

Un espectador ve, en una semana tipo, vivir y trabajar a 30 policías, 7 abogados, 3 jueces y un solo ingeniero o científico. En la televisión hay diez veces más delitos que en la vida real.

Este dato, de nuevo, invita a la reflexión final.

NÍHIL ÓBSTAT . IMPRIMÁTUR 


\section{Bibliografía}

BARRI OS, Leoncio (1996): Literatura para recrear y educar. Editorial Caracas.

GARCíA GALERA, Carmen (2000): Televisión, violencia e infancia: el impacto de los medios. Gedisa. Madrid.

LEVINE, Madeline (1998): La violencia en los medios de comunicación. Editorial Norma. Madrid.

FERNÁNDEZ VILLANUEVA, Concepción (1998): Jóvenes violentos. Causas psicológicas de la violencia en grupo. Icaria. Madrid

MARTÍNEZ CRIADO, Gerardo (1998): El juego y el desarrollo infantil. Ediciones Octaedro. Madrid.

SAPIR, Edgard (1973): Lingüística y significación. Editorial Salvat. Barcelona. 